\title{
Effect of active application of self-etching ceramic primer on the long-term bond strength of different dental CAD/CAM materials
}

\author{
João-Paulo-Mendes Tribst ${ }^{1}$, Pedro-Jacy-Santos Diamantino ${ }^{2}$, Maiara-Rodrigues de Freitas ${ }^{3}$, Isabela-Vitelli \\ Tanaka $^{2}$, Lais-Regiane Silva-Concílio ${ }^{1}$, Renata-Marques de Melo ${ }^{4}$, Guilherme-de Siqueira-Ferreira-Anzaloni \\ Saavedra $^{4}$
}

${ }^{1}$ DDS, MSc, PhD, Department of Dentistry, University of Taubaté (UNITAU), Taubaté 12020-270, SP, Brazil

${ }^{2}$ DDs, MSc, PhD student, Department of Dental Materials and Prosthodontics, São Paulo State University (Unesp), Institute of Science and Technology, São José dos Campos, São Paulo, Brazil

${ }^{3}$ DDS, MSc, PhD student, Department of Dentistry, University of Taubaté (UNITAU), Taubaté 12020-270, SP, Brazil

${ }^{4}$ DDs, MSc, PhD, Department of Dental Materials and Prosthodontics, São Paulo State University (Unesp), Institute of Science and Technology, São José dos Campos, São Paulo, Brazil

Correspondence:

Department of Dental Materials and Prosthodontics

São Paulo State University (Unesp)

Institute of Science and Technology

São José dos Campos / SP, Brazil

Av Engenheiro Francisco José Longo, 777

Jardim São Dimas, São José dos Campos

São Paulo, Brazil

joao.tribst@unesp.br

Tribst JPM, Diamantino PJS, de Freitas MR, Tanaka IV, Silva-Concílio LR, de Melo RM, Saavedra GSFA. Effect of active application of selfetching ceramic primer on the long-term bond strength of different dental CAD/CAM materials. J Clin Exp Dent. 2021;13(11):e1089-95.

Received: $21 / 06 / 2021$ Accepted: 20/09/2021

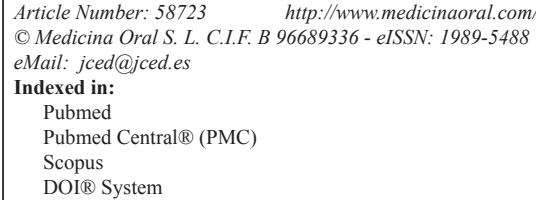

\begin{abstract}
Background: The objective of this in vitro study was to evaluate the effect of the active application of self-etching ceramic primer (ME\&P) on the bond strength of different dental CAD/CAM materials (Lithium Disilicate ceramic (LD), Leucite ceramic (LE), Zirconia reinforced lithium silicate ceramic (ZLS), and Hybrid ceramic (HC)) with thermocycling aging.

Material and Methods: The samples were randomly divided into 16 groups $(n=20)$. Dual resin cement cylinders were made and light cured for $10 \mathrm{~s}\left(1.200 \mathrm{~mW} / \mathrm{cm}^{2}\right)$ for the shear bond strength test. 3-way ANOVA revealed that the factors were statistically significant $(P<0.05)$.

Results: The aging process had a negative impact on the bond strength for all groups except for Lithium Disilicate, with active application. ZLS and LE showed promising results with high bond strength values for the ME\&P active application; however, after aging the bond strength value was significantly reduced. HC showed reduced bond strength values regardless the ME\&P application.

Conclusions: In order to obtain a durable bond strength, the recommended protocol of $20 \mathrm{~s}$ of active application followed by $40 \mathrm{~s}$ of sitting time in the self-etching ceramic primer should be followed when using reinforced-glass ceramics as restorative materials.
\end{abstract}

Key words: Dentistry, dental materials, silane, shear strength, computer-aided design. 


\section{Introduction}

With the main objective of preserving the remaining dental structures and to recover masticatory function and aesthetics, the dental ceramics are widely applied as biomaterials in Dentistry (1). In addition to being biocompatible, these materials can mimics the optical characteristics of teeth in a satisfactory way (2), present good mechanical properties and long-term color stability $(3,4)$. However, dental ceramics strength is usually inversely proportional to the aesthetics $(5,6)$.

Nowadays, clinicians and researchers must know the available dental materials that can be indicated to make the restorative procedure more predictable and safer for the patients. Therefore, reinforced glass ceramics (Leucite, Lithium disilicate and Zirconia reinforced lithium silicate based materials), as well as hybrid ceramics (polymer infiltrated ceramic network) are versatile materials that combine proper aesthetic and mechanical properties to manufacture crowns, partial restorations (inlays and onlays) and implant-supported restorations (7). These materials can only be applied in dentistry due to the advancement of CAD/CAM (Computer aided design and computer aided manufacturing) technology, which allows the machining of indirect restorations with excellent structural characteristics.

Despite the restorative material selection, for a predictable treatment, the adhesive procedure should be properly performed aiming to achieve the most durable bond strength in long-term follow-ups. Therefore, the restorative material should receive a surface treatment that will improve the bondability with the resin cement. Conventionally, surface treatment is performed using hydrofluoric acid (HF) etching, which creates mechanical retentions and makes the surface more reactive followed by the application of silane coupling agent, whose function is to unite the inorganic portion of the ceramic with the organic portion of the resin cement (8-10). However, in order to simplify the process and to reduce the use of hazardous HF, using a self-etching ceramic primer (Monobond Etch \& Prime, Ivoclar Vivadent, Schaan, Liechtenstein) is an excellent alternative.

The principal advantage of self-etching ceramic primer (ME\&P) usage is the decrease in the number of clinical steps. This makes the procedure less sensitive to the technique. In addition, by having a single exposure time for all ceramic materials, the ME\&P allows standardization, which contributes to the simplicity of the luting procedure $(10,11)$. The manufacturer recommendation is to apply the ME\&P on the ceramic surface actively for 20 seconds with the aid of a microbrush and then let sitting for 40 seconds. Until now, however, there is no report in the literature that justifies if this actively application presents any beneficial effect to the bond strength or if 60 seconds of exposure timing could be performed as a simpler process.
It is also important to evaluate the bond strength of dental materials in long-term simulations, performing aging procedures. This is important since the oral environment is an unfriendly medium to the restorative materials, which will stress the adhesive interface, impair the bond strength and reduce the restoration survival as long it remains in position. A valuable method, widely applied in literature, is the use of thermocycling aging which mimics some of the aspects of the oral cavity temperature variation (12).

Therefore, the aim of the present study was to evaluate the effect of the active application of a self-etching ceramic primer on the bond strength of different $\mathrm{CAD} /$ CAM materials before and after aging simulation. The null hypothesis was that the different surface treatment would not affect the bond strength regardless the restorative materials and aging process.

\section{Material and Methods}

-Sample preparation

Three hundred twenty (320) blocks of four different CAD/CAM materials (Lithium Disilicate based ceramic (LD), Leucite based ceramic (LE), Zirconia reinforced lithium silicate based ceramic (ZLS), and Hybrid ceramic (HC)) were cut with a low-speed diamond saw using water cooling into $6 \times 6 \times 2 \mathrm{~mm}$ blocks verified with the aid of a digital caliper (Eccofer, Curitiba, PR, Brazil). The block surfaces were flattened with decreasing granulated SIC paper (\#600, \#800, \#1000 and \#1200 - 3M, St. Paul, MN, USA) using an automatic polishing machine (Ecomet 250 Grinder Polisher, Buehler, Illinois, USA). The lithium (di)silicate samples were subsequently crystalized in a ceramic furnace of the respective ceramic systems according to the manufacturer's recommendations. The materials' respective manufacturers and compositions are summarized in Table 1.

The 320 blocks were embedded in chemically activated acrylic resin (TDV, TDV Dental Ltda, Pomerode, Santa Catarina, Brazil) using a polyvinylchloride cylinders mold. Then, the samples were randomly divided into sixteen groups $(n=20)$, according to the factors: "Ceramic primer application (active or not)", "Aging simulation (present or not)", and "Ceramic type (HC, LD, LE or ZLS)".

Before the surface treatment procedures, all ceramic blocks were immersed in distilled water and ultrasonically cleaned for 5 min (Cristófoli Equipamentos de Biossegurança LTDA, Campo Mourão, Brazil).

-Surface treatments

Each group of ceramic material was randomly divided in two other subgroups according to the surface treatment. To evaluate the effect of self-etching ceramic primer active application, two different surface treatments were performed with the same exposing time: In the conventional treatment (T0), the ceramic surface received an active application of self-etching glass ceramic primer 
Table 1: Materials used in this study and their respective manufacturers and compositions.

\begin{tabular}{|c|c|}
\hline Material/Brand name & Composition \\
\hline $\begin{array}{c}\text { LE } \\
\text { Leucite based ceramic, IPS e.max CAD, Ivoclar } \\
\text { Vivadent, AG, Schaan, Liechtenstein. }\end{array}$ & $\begin{array}{l}\left(64.9 \% \mathrm{SiO}_{2}, 16.25 \% \mathrm{Al}_{2} \mathrm{O}_{3}, 11.85 \% \mathrm{~K}_{2} \mathrm{O}\right. \\
\left.5.37 \% \mathrm{Na}_{2} \mathrm{O}, 1.56 \% \mathrm{CaO}\right)\end{array}$ \\
\hline $\begin{array}{l}\text { LD } \\
\text { Lithium disilicate based ceramic, IPS e.max CAD, } \\
\text { Ivoclar Vivadent, AG, Schaan, Liechtenstein. }\end{array}$ & $\begin{array}{c}\left(57-80 \% \mathrm{SiO}_{2}, 11-19 \% \mathrm{Li}_{2} \mathrm{O}, 0-13 \% \mathrm{~K}_{2} \mathrm{O}, 0-11 \%\right. \\
\mathrm{P}_{2} \mathrm{O}_{5}, 0-8 \% \mathrm{ZrO}_{2}, 0-8 \% \mathrm{ZnO}, 0-5 \% \mathrm{Al}_{2} \mathrm{O}_{3}, 0-5 \% \\
\mathrm{MgO})\end{array}$ \\
\hline $\begin{array}{l}\text { ZLS } \\
\text { Zirconia reinforced lithium silicate based ceramic. } \\
\text { Vita Suprinity, Vita Zahnfabrik. }\end{array}$ & $\begin{array}{c}\left(56-64 \% \mathrm{SiO}_{2}, 15-21 \% \mathrm{LiO}_{2}, 1-4 \% \mathrm{~K}_{2} \mathrm{O}, 3-8 \%\right. \\
\mathrm{P}_{2} \mathrm{O}_{5}, 1-4 \% \mathrm{Al}_{2} \mathrm{O}_{3}, 0-4 \% \mathrm{CeO}_{2} \text { and } 0-6 \% \text { pigments } \\
\left.\text { and } 10 \% \mathrm{ZrO}_{2}\right)\end{array}$ \\
\hline $\begin{array}{c}\text { HC } \\
\text { Hybrid ceramic. Vita Enamic, Vita Zahnfabrik. }\end{array}$ & $\begin{array}{c}\left(58-63 \% \mathrm{SiO}_{2}, 20-23 \% \mathrm{Al}_{2} \mathrm{O}_{3}, 6-11 \% \mathrm{Na}_{2} \mathrm{O}, 4-6 \%\right. \\
\left.\mathrm{K}_{2} \mathrm{O}, 0.5-2 \% \mathrm{~B}_{2} \mathrm{O}_{3},<1 \% \mathrm{CaO} \text { and }<1 \% \mathrm{TiO}_{2}\right)\end{array}$ \\
\hline $\begin{array}{c}\text { Self-etching ceramic primer. } \\
\text { Monobond Etch and Prime, } \\
\text { Ivoclar Vivadent, } \mathrm{AG}, \text { Schaan, Liechtenstein. }\end{array}$ & $\begin{array}{l}\text { Ammonium polyfluoride, trimethoxypropyl } \\
\text { methacrylate, alcohols, water }\end{array}$ \\
\hline $\begin{array}{l}\text { Resin cement. } \\
\text { Variolink N, Ivoclar Vivadent, AG, } \\
\text { Schaan, Liechtenstein. }\end{array}$ & $\begin{array}{l}\text { Bis- GMA, urethane dimethacrylate, and } \\
\text { triethylene glycol dimethacrylate. The inorganic } \\
\text { fillers are barium glass, ytterbium } \\
\text { trifluoride, Ba-Al-fluorosilicate glass, and }\end{array}$ \\
\hline
\end{tabular}

(Monobond Etch \& Prime, Ivoclar Vivadent, Schaan, Liechtenstein) for $20 \mathrm{~s}$, followed by $40 \mathrm{~s}$ of setting. In the experimental treatment (T1), the ceramic surface received self-etching glass ceramic primer (Monobond Etch \& Prime, Ivoclar Vivadent, Schaan, Liechtenstein) for 60 s of setting (Fig. 1). For both treatments, the samples were then washed with running tap water and dried with an oil-free air jet.
After surface treatment, a cylinder of resin cement (Variolink N, Ivoclar Vivadent, Schaan, Liechtenstein) was made on the ceramics surfaces. A Teflon matrix was used to standardize the adhesive area and height of the cylinder. After fitting the matrix to the surfaces, the resin cement was added to the matrix, light cured for 10 $\mathrm{s}\left(1.200 \mathrm{~mW} / \mathrm{cm}^{2}\right.$ - Bluephase N, Ivoclar Vivadent, Liechtenstein).

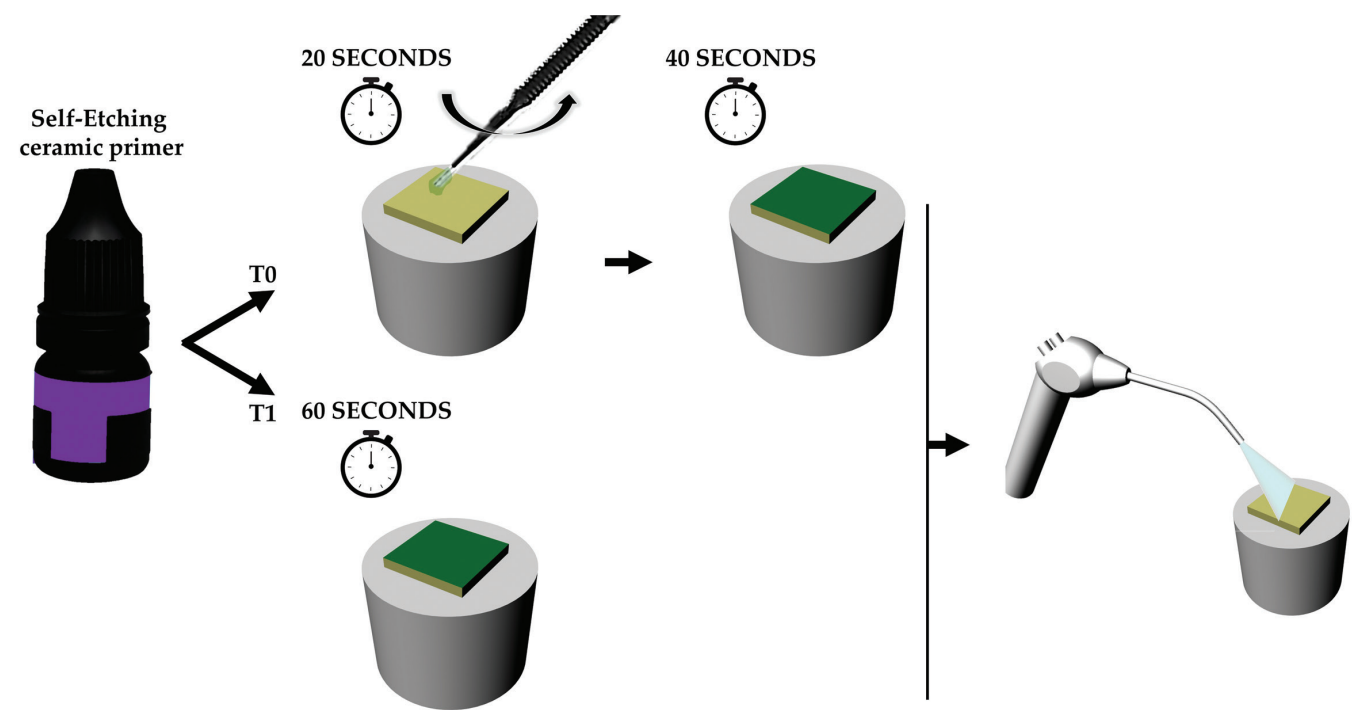

Fig. 1: Schematic illustration showing the evaluated surface treatments protocols. T0 was performed following the manufacture's recommendation using 20 seconds of scrubbing and 40 seconds of reaction time totaling 60 seconds. T1 was performed with 60 seconds of reaction time. 
-Resin cement application

After 24 hours, the matrices were removed and half of the samples (block + resin cylinder) were immediately submitted to shear bond strength test, while the other half was submitted to the thermocycling aging protocol. The thermocycling protocol consisted of 10.000 cycles of alternate 30 -s baths at $5^{\circ} \mathrm{C}$ and $55^{\circ} \mathrm{C}$, with a 5 -s interval between immersions using a thermocycler (Nova Etica, São Paulo, Brazil).

The Shear bond strength test ( $50 \mathrm{KgF}, 0.5 \mathrm{~mm} / \mathrm{min}$ ) was carried out in an universal testing machine (DL-1000, EMIC, São José dos Campos, Brazil). Specimens had the cement / ceramic interface hold perpendicularly to the horizontal plane by a device. The load was applied at the base of the cylinder on the adhesive interface, using an orthodontic wire $(0.2 \mathrm{~mm}$ diameter $)$ at a speed of $0.5 \mathrm{~mm} / \mathrm{min}$ and load cell of $50 \mathrm{KgF}$ until fracture of the specimen (13). The calculation of the bond strength was performed by the formula: $\mathrm{R}=\mathrm{F} / \mathrm{A}$, where $\mathrm{R}=$ adhesive strength $(\mathrm{MPa}) ; \mathrm{F}=$ force $(\mathrm{N}) ; \mathrm{A}=$ interfacial area $(\mathrm{mm})$. The adhesive area of each ceramic block was defined by the area of a circle using the formula $\mathrm{A}=\pi \mathrm{r}^{2}$, where $\pi=$ 3.14 and $r=1 \mathrm{~mm}$ (radius of the cylinder), resulting in a cross-sectional area of $3.14 \mathrm{~mm}^{2}$ (14).

Analysis of variance (3-way ANOVA) and Tukey's test (5\%) were used to compare data from the groups. Using the OpenEpi website, a power of $95.82 \%$ was calculated using a two-sided $95 \%$ confidence interval.

\section{Results}

Three-way ANOVA revealed that the factors "Material" $(p=0.001)$, "Surface treatment" $(p=0.000)$ and "Aging" ( $p=0.000)$ were statistically significant. In addition, the interactions of the factors were also significant. The interaction of all evaluated factors "Material* Surface Treatment *Aging" was significant $(p=0.038)$ and used to perform the Tukey test grouping comparisons to show the difference between the groups (Table 2). When all experimental groups were compared, the use of. The means ( \pm $\mathrm{SD}$ ) of shear bond strength and the comparison between the experimental groups are summarized in Table 3.
According to the results, the aging process has a negative effect to the bond strength for all groups except to Lithium Disilicate based ceramic with active application of the self-etching ceramic primer that has showed bond strength values statistically similar before (14.83 \pm $4.78 \mathrm{MPa})$ and after $(12.54 \pm 2.90 \mathrm{MPa})$ aging. However, aged samples without the primer scrubbing showed that the bond strength can be negatively affected even for this ceramic material (decreasing from 12.73 \pm 2.74 $\mathrm{MPa}$ to $9.08 \pm 4.58 \mathrm{MPa}$ ). ZLS and LE showed promising results with higher bond strength values for the active application of the self-etching ceramic primer (13.06 \pm 4.13 and $10.92 \pm 1.75 \mathrm{MPa}$ respectively), however after aging the bond strength value was significantly reduced for both materials $(3.20 \pm 1.13$ and $4.16 \pm 2.12$ MPa respectively).

When considering the surface treatment with active application, LE and ZLS are statistically similar before (5.60 \pm 2.32 and $7.42 \pm 2.78$ respectively) and after aging simulation $(1.11 \pm 1.01$ and $3.20 \pm 1.13 \mathrm{MPa}$ respectively). HC showed similar and reduced bond strength values regardless the primer application method (7.66 \pm 3.95 $\mathrm{MPa}$ for $\mathrm{T} 0$ and $7.33 \pm 3.71 \mathrm{MPa}$ for T1). This same effect was also noticed after the aging simulation for this restorative material $(2.65 \pm 1.33 \mathrm{MPa}$ for $\mathrm{T} 0$ and $2.53 \pm$ 1.76 MPa for T1).

\section{Discussion}

The purpose of this study was to evaluate the effect of the active application of a self-etching ceramic primer on the bond strength of different CAD/CAM materials. Results presented statistically difference between experimental groups considering the factors interaction. Therefore, the null hypothesis of the study was rejected.

The protocol using a self-etch ceramic primer is a simpler and safer alternative to the conventional protocol with hydrofluoric acid for silica-based ceramics clinical follow-up reporting restorations. This aproach has already a satisfactory esthetic and functional performance, color stability, surface and marginal integrity, and absence of cracks and debonding (15). Therefore, an optimal

Table 2: Three-way ANOVA of bond strength according to the factors: material, surface treatment and aging.

\begin{tabular}{|l|c|c|c|c|c|}
\hline Source & DF & Adj SS & Adj MS & F-Value & $P$-Value \\
\hline Material & 3 & 3248.0 & 1082.68 & 56.38 & 0.001 \\
\hline Surface treatment & 1 & 448.9 & 448.95 & 23.38 & 0.000 \\
\hline Aging & 1 & 1194.2 & 1194.25 & 62.19 & 0.000 \\
\hline Material* surface treatment & 3 & 187.5 & 62.51 & 3.25 & 0.022 \\
\hline Material*aging & 3 & 370.0 & 123.33 & 6.42 & 0.012 \\
\hline Surface treatment *aging & 1 & 94.0 & 93.95 & 4.89 & 0.028 \\
\hline Material* surface treatment *aging & 3 & 47.6 & 15.87 & 0.83 & 0.038 \\
\hline Error & 304 & 5838.0 & 19.20 & & \\
\hline Total & 319 & 11428.3 & & & \\
\hline
\end{tabular}


Table 3: Average bond strength (MPa), standard deviation and TUKEY test (95\%) according to the evaluated groups.

\begin{tabular}{|l|c|c|c|c|c|c|c|c|c|}
\hline $\begin{array}{l}\text { Material* } \\
\text { Surface Treatment * } \\
\text { Aging }\end{array}$ & $\begin{array}{c}\text { Bond Strength } \\
\text { (MPa) }\end{array}$ & \multicolumn{5}{|c|}{ Grouping } \\
\hline LD*T0*No & 20 & $14.83 \pm 4.78$ & a & & & & & & \\
\hline ZLS*T0*No & 20 & $13.06 \pm 4.13$ & a & b & & & & & \\
\hline LD*T1*No & 20 & $12.73 \pm 2.74$ & a & b & & & & & \\
\hline LD*T0*Yes & 20 & $12.54 \pm 2.90$ & a & b & & & & & \\
\hline LE*T0*No & 20 & $10.92 \pm 1.75$ & a & b & c & & & & \\
\hline LD*T1*Yes & 20 & $9.08 \pm 4.58$ & & b & c & d & & & \\
\hline HC*T0*No & 20 & $7.66 \pm 3.95$ & & & c & d & e & & \\
\hline ZLS*T1*No & 20 & $7.42 \pm 2.78$ & & & c & d & e & & \\
\hline HC*T1*No & 20 & $7.33 \pm 3.71$ & & & c & d & e & f & \\
\hline LE*T1*No & 20 & $5.60 \pm 2.32$ & & & & d & e & f & g \\
\hline ZLS*T0*Yes & 20 & $5.14 \pm 1.62$ & & & & d & e & f & g \\
\hline LE*T0*Yes & 20 & $4.16 \pm 2.12$ & & & & & e & f & g \\
\hline ZLS*T1*Yes & 20 & $3.20 \pm 1.13$ & & & & & e & f & g \\
\hline HC*T1*Yes & 20 & $2.65 \pm 1.33$ & & & & & & f & g \\
\hline HC*T0*Yes & 20 & $2.53 \pm 1.76$ & & & & & & g \\
\hline LE*T1*Yes & 20 & $1.11 \pm 1.01$ & & & & & & g \\
\hline & & & & & & \\
\hline & & & & & & & \\
\hline
\end{tabular}

bond strength can only be achieved when the surface treatment will be properly performed.

A previous study investigated the influence of simplified ceramic surface treatments on shear bond strength of resin-luting cement and lithium disilicate ceramic. The authors indicated that the self-etching ceramic primer is a satisfactory alternative to replace the use of hydrofluoric acid in dental treatments (16). There is also reports that ME\&P can be applied as an alternative also for for Leucite based ceramic $(10,17)$. The present study, however suggests that the manufacturers protocol should be followed regardless the restorative material.

According to the literature, when the treating the $\mathrm{CAD} /$ CAM materials with self-etching ceramic primer, it is expected the occurrence of the a physicochemical conditioning through a mild etchant (ammonium polifluoride) and a trimethoxypropyl methacrylate for silanization, resulting in a reduced number of defects on the ceramic surface (18). This topographical change is more superficial than those produced by conventional acid etching, which might favor a better fatigue performance (18) and fracture load (17). The same principle can be applied to the bond strength durability when the active application is part of the protocol.

The manufacturer recommends that after being actively applied during 20 seconds, the ME\&P must be left in contact with the ceramic surface to let it react and then it must be washed with water. This step is required to remove the acid etchant and reaction byproducts leaving only a thin layer of silane that is chemically bonded to the ceramic surface. It seems that the water washing step is an effective step to remove residuals and so, an additional treatment might not be necessary (19).

A previous study analyzed the effect of different ceramic primers and post-silanization protocols on physicochemical and morphological characteristics of a lithium disilicate glass ceramic. One of the tested surface treatments was the ME\&P application, comparing the effect of additional drying with air (30 s) at room temperature than the recommended time. However, the authors did not found influence between these different protocols for the bond strength when self-etching ceramic primer was applied (19). Therefore, we can suggest that the silane exposing time seems to be relevant to the bond strength. In addition, the use of self-etching ceramic primer can produce a lower surface free energy that could be an indicative that the silane molecules might remain effectively bonded to the available hydroxyls on ceramic surface (19).

A previous study evaluated the effect of different scrubbing times (between 5 and 60 seconds) and reaction time (20 and 40 seconds) in two CAD/CAM materials (feldspathic and Lithium disilicate based ceramics) (20). The authors reported that increasing the scrubbing time or the reaction time, a higher glass matrix dissolution will be present, increasing the bond strength for lithium disilicate. For the Feldspathic material, there was no difference between the evaluated protocols (20). Ac- 
cording to the authors, the bonding mechanism of the self-etching ceramic primer can be related with the interaction between the ceramic surface ions and functional phosphoric monomers rather than methacrylate silane bonding (20). The present study corroborates with the fact that the scrubbing step is essential for the self-etching silane etching performance.

The results of previous reported accelerated aging tests confirmed that the stability and protective capacity of a silane film to environmental stimuli is dependent on the chemical reactivity, hydrophobicity, extent of network cross-linking and film thickness (21). An additional factor that add for the positive effect of ME\&P is the water rinsing and air-drying stage after application, which remove more effectively the loosely bound fractions of $\gamma$-methacryloxypropyl trimethoxysilane and bipodal bis-triethoxysilyl ethane (21). However, it seems that this effect can only occur when the scrubbing is performed on the ceramic surface, otherwise the water rising will remove not-reacted silane instead residual components.

The strength and durability of the bond between ceramic and resin cement depends on multiple factors including the type of treatment selected, which is in turn governed by the microstructure of the ceramic material (22). It is also reported that the one-step ceramic primer can be used successfully with the guarantee of excellent bond strength for Leucite based ceramic and reinforced glass ceramics $(22,23)$. However it was also reported that the effect of different surface treatments can affect the biaxial flexure strength, roughness and microstructure of lithium silicate and dislocated reinforced ceramics after cementation and mechanical cycling (24). Similar to the present study, the authors reported the use of self-etching ceramic primer in the ZLS actively applied for $20 \mathrm{~s}$, then reacting for another $40 \mathrm{~s}$. That present study complement these findings showing the ZLS has a good immediate bond strength, however it can be affected by the aging process.

According to an in vitro study, the self-etching ceramic primer can be an optimal alternative to Lithium Disilicate based ceramics conditioning, being less hazardous option to treat the ceramic surface (25). However, its use is not recommended for polycrystalline materials such Yttria-stabilized tetragonal zirconia polycrystal (YTZP). Maybe, some interaction between the zirconia present in the ZLS could be the responsible by the low bond strength after aging simulation. However, this hypothesis should be confirmed in further studies.

Comparing the same CAD/CAM materials that were evaluated in the present study, a previous report compared the use of self-etching ceramic primer for $60 \mathrm{~s}(20 \mathrm{~s}$ of application and $40 \mathrm{~s}$ of reaction time) and $120 \mathrm{~s}(40 \mathrm{~s}$ of application and $80 \mathrm{~s}$ of reaction time) with conventional hydrofluoridric acid etching (26). The authors found that hybrid ceramic had a statistically significantly lower bond strength than lithium disilicate glass-ceramic, whereas the other materials did not differ from the lithium disilicate glass-ceramic (26). In the present study, observing only the results for the conventional treatment (T0) without aging, a similar result can be observed between the present study and the reported literature. In addition to the results and similar materials, the authors defined that future studies exploring different application and reaction times might be useful to come to a definite conclusion about the duration of self-etching ceramic primer $(25,26)$. In this sense, the present study fits this suggestion, demonstrating that the active scrubbing during the self-etching ceramic application is an important step that should not be neglected regardless the CAD/ CAM material, especially when long-term bond strength durability is considered.

Several tests can be used in order to verify the bond strength of the ceramic-cement interfaces, such as shear, micro-shear, tensile and micro-tensile. The microtensile bond test is a very useful tool for bond strength investigations, since it can promote a uniform distribution of stresses along the adhesive interface in comparison with the other tests (27). However, pre-testing failure will still occur as a problem for the testing in situations with low bond strength test (27), as well as the sectioning procedures of these tests can induce residual stresses, decreasing the results reliability (28). In this sense, shear bond strength test is widely applied to evaluate the bond strength between the adhesive interfaces of ceramic/ resin cement (28-30). Another important aspect to use the shear bond strength test, is the high amount of shear stress concentration that occurs during chewing load incidence in an adhesively luted indirect restoration (31). Therefore, this in vitro test can be indicated to simulate one of the predominant stress resultants responsible to increase the adhesive failure risk calculated in dental materials (32).

A restoration in the oral cavity is challenged in many ways: it is subjected to complex occlusal forces, immersed in saliva and exposed to food and beverages with various $\mathrm{pH}$, chemistries, and temperatures (16). However, because this is an in vitro study, these reported factors are not present during the aging simulation and are part of the study's limitations. In addition, there is no incidence of chewing loads in the samples or progressive mechanical fatigue that could affect the bond strength behavior. However, further studies should be carried out to complement the present findings.

\section{Conclusions}

In order to guarantee a durable bond strength, $20 \mathrm{~s}$ of active application followed by $40 \mathrm{~s}$ of sitting time for the self-etching ceramic primer should be performed when using reinforced-glass ceramics as restorative materials. 
The lithium disilicate based ceramic demonstrated the highest values of bond strength in comparison with the other evaluated materials, even after the aging simulation.

\section{References}

1. Fu L, Engqvist H, Xia W. Glass-ceramics in dentistry: A review. Materials (Basel). 2020;13:1049.

2. Mainjot AK, Dupont NM, Oudkerk JC, Dewael TY, Sadoun MJ. From artisanal to CAD-CAM blocks: State of the art of indirect composites: State of the art of indirect composites. J Dent Res. 2016;95:487-95.

3. Oh GJ, Park SW, Yun KD, Lim HP, Son HJ, Koh JT, et al. Effect of transition metal dopants on mechanical properties and biocompatibility of zirconia ceramics. J Nanosci Nanotechnol. 2013;13:4252-5.

4. Saavedra G, Ariki EK, Federico CD, Galhano G, Zamboni S, Baldissara $\mathrm{P}$, et al. Effect of acid neutralization and mechanical cycling on the microtensile bond strength of glass-ceramic inlays. Oper Dent. 2009;34:211-6.

5. Borba M, de Araújo MD, Fukushima KA, Yoshimura HN, Cesar PF, Griggs JA, et al. Effect of the microstructure on the lifetime of dental ceramics. Dent Mater. 2011;27:710-21.

6. Gonzaga CC, Cesar PF, Miranda WG Jr, Yoshimura HN. Slow crack growth and reliability of dental ceramics. Dent Mater. 2011;27:394406.

7. Elsaka SE, Elnaghy AM. Mechanical properties of zirconia reinforced lithium silicate glass-ceramic. Dent Mater. 2016;32(7):908-14. 8. Ozcan M, Vallittu PK. Effect of surface conditioning methods on the bond strength of luting cement to ceramics. Dent Mater. 2003;19:72531 .

9. Silva TM da, Fernandes VVB Junior, Santana RS de, Marinho RM de M, Valera MC, Bresciani E. Influence of Zingiber officinale extract on push-out bond strength of glass-fiber post. Braz Dent J. 2018;29:93-8.

10. Tribst J, Anami LC, Özcan M, Bottino MA, Melo RM, Saavedra G. Self-etching primers vs acid conditioning: Impact on bond strength between ceramics and resin cement. Oper Dent. 2018;43:372-9.

11. Lyann SK, Takagaki T, Nikaido T, Uo M, Ikeda M, Sadr A, et al. Effect of different surface treatments on the tensile bond strength to lithium disilicate glass ceramics. J Adhes Dent. 2018;20:261-8.

12. Ozcan M, Barbosa SH, Melo RM, Galhano GAP, Bottino MA. Effect of surface conditioning methods on the microtensile bond strength of resin composite to composite after aging conditions. Dent Mater. $2007 ; 23: 1276-82$.

13. Araújo AMM de, Januário AB do N, Moura DMD, Tribst JPM, Özcan M, Souza ROA. Can the application of multi-mode adhesive be a substitute to silicatized/silanized Y-TZP ceramics? Braz Dent J. 2018;29:275-81.

14. AMO Dal Piva, JPM Tribst, MA Bottino. Evaluation of shear bond strength and shear stress on zirconia reinforced lithium silicate and high translucency zirconia. J Oral Res. 2018;7:30-6.

15. Souza R, da Silva NR, de Miranda LM, de Araújo GM, Moura D, Barbosa H. Two-year follow-up of ceramic veneers and a full crown treated with self-etching ceramic primer: A case report. Oper Dent. 2020;45:352-8.

16. Guimarães HAB, Cardoso PC, Decurcio RA, Monteiro LJE, de Almeida LN, Martins WF, et al. Simplified surface treatments for ceramic cementation: Use of Universal Adhesive and self-etching ceramic primer. Int J Biomater. 2018;2018:2598073.

17. Tribst JPM, Dal Piva AM de O, Lopes GC, Borges ALS, Bottino MA, Özcan M, et al. Biaxial flexural strength and Weilbull characteristics of adhesively luted hybrid and reinforced CAD/CAM materials to dentin: effect of self-etching ceramic primer versus hydrofluoric acid etching. J Adhes Sci Technol. 2020;1-16.

18. Tribst JPM, Monteiro JB, Venturini AB, Pereira GKR, Bottino MA, Melo RM de, et al. Fatigue failure load of resin-bonded simplified lithium disilicate glass-ceramic restorations: Effect of ceramic conditioning methods. J Adhes Dent. 2019;21:373-81.
19. Moreno MBP, Murillo-Gómez F, de Goes MF. Physicochemical and morphological characterization of a glass ceramic treated with different ceramic primers and post-silanization protocols. Dent Mater. 2019;35:1073-81

20. Cardenas AFM, Quintero-Calderon AS, Siqueira FSF de, Campos VS, Wendlinger M, Pulido-Mora CA, et al. Do different application modes improve the bonding performance of self-etching ceramic primer to lithium disilicate and feldspathic ceramics? J Adhes Dent. 2019;21:319-27.

21. Dimitriadi M, Zinelis S, Zafiropoulou M, Silikas N, Eliades G. Self-etch silane primer: Reactivity and bonding with a lithium disilicate ceramic. Materials (Basel). 2020;13:641.

22. Al-Harthi AA, Aljoudi MH, Almaliki MN, El-Banna KA. Laboratory study of micro-shear bond strength of two resin cements to leucite ceramics using different ceramic primers. J Contemp Dent Pract. 2018; 19:918-24.

23. Maier E, Bordihn V, Belli R, Taschner M, Petschelt A, Lohbauer U, et al. New approaches in bonding to glass-ceramic: Self-etch glass-ceramic primer and universal adhesives. J Adhes Dent. 2019;21:209-17. 24. Lima CM, Silva NR da, Martins JD, Miranda JS, Tanaka R, Souza RO de AE, et al. Effect of different surface treatments on the biaxial flexure strength, Weibull characteristics, roughness, and surface topography of bonded CAD/CAM silica-based ceramics. Dent Mater. 2021;37:e151-61.

25. Wille S, Lehmann F, Kern M. Durability of resin bonding to lithium disilicate and Zirconia ceramic using a self-etching primer. J Adhes Dent. 2017;19:491-6.

26. Donmez MB, Okutan Y, Yucel MT. Effect of prolonged application of single-step self-etching primer and hydrofluoric acid on the surface roughness and shear bond strength of CAD/CAM materials. Eur J Oral Sci. 2020;128:542-9.

27. Sano H, Chowdhury AFMA, Saikaew P, Matsumoto M, Hoshika $\mathrm{S}$, Yamauti M. The microtensile bond strength test: Its historical background and application to bond testing. Jpn Dent Sci Rev. 2020;56:2431 .

28. Secilmis A, Ustun O, Kecik Buyukhatipoglu I. Evaluation of the shear bond strength of two resin cements on different CAD/CAM materials. J Adhes Sci Technol. 2016;30:983-93.

29. Veríssimo AH, Moura DMD, Tribst JPM, Araújo AMM de, Leite FPP, Souza RO de AE. Effect of hydrofluoric acid concentration and etching time on resin-bond strength to different glass ceramics. Braz Oral Res. 2019;33:e041.

30. Moura DMD, Araújo AMM de, Souza KB de, Veríssimo AH, Tribst JPM, Souza RO de AE. Hydrofluoric acid concentration, time and use of phosphoric acid on the bond strength of feldspathic ceramics. Braz Oral Res. 2020;34:e018.

31. Dal Piva AM de O, Tribst JPM, de Carvalho PCK, Uemura ES, Paes Junior TJ de A, Borges ALS. Effect of surface treatments on the bond repair strength of resin composite to different artificial teeth. Appl Adhes Sci. 2018;6.

32. Dal Piva AM de O, Tribst JPM, Borges ALS, Souza RO de AE, Bottino MA. CAD-FEA modeling and analysis of different full crown monolithic restorations. Dent Mater. 2018;34:1342-50.

\section{Conflict of interest}

Non declared. 